SAŠA STEPANOV, Ph.D. ${ }^{1,2}$

(Corresponding author)

E-mail: sasa.stepanov@gmail.com

ZORAN ŠUNJK, M.Sc. ${ }^{2}$

E-mail: sunjkaz@bas.rs

ĐORĐE ČABILOVSKI, M.Sc. ${ }^{3}$

E-mail: djcabilovski@gmail.com

${ }^{1}$ Faculty of Applied Management, Economics and Finance

Jevrejska 24, Belgrade, 11000, Serbia

2 BAS a.d., Belgrade Bus Station

Železnička 4, Belgrade, 11000, Serbia

${ }^{3}$ Ministry of Defense of the Republic of Serbia

Gundulićeva BB, Zrenjanin, 23000, Serbia
Intelligent Transport Systems (ITS)

Original Scientific Paper

Submitted: 2 Nov. 2018

Accepted: 28 June 2019

\title{
INTELLIGENT PARKING SPACE CONTROL IN A SYSTEM WITH RESERVATIONS
}

\begin{abstract}
The aim of the system with reservations is to reduce the time the user needs to reach the parking space as well as to rationalize the controlling of demands in the central business districts. When applying the system with reservations, it is necessary to know the user's travel time to the parking space, as well as the time of parking. The sum of these two periods represents the parking space "occupancy". The purpose of this paper is to suggest a model for determining the total occupancy of a parking space based on 1) the user's travel time to the parking space; 2) the user's duration of parking. Considering the fact that we are dealing with values which cannot be exactly estimated, the fuzzy logic system (FLS) is used. A Neural Network (NN) is trained on the basis of data about the estimated values of the input parameters and the real value of output parameters. Thus, a hybrid model of fuzzy logic and neural networks (ANFIS) is obtained. Finally, there is an example based on the real data which shows the application possibilities of this model.
\end{abstract}

\section{KEY WORDS}

parking space control; reservation system; fuzzy logic; Neural Networks;

\section{INTRODUCTION}

Searching for a parking space in a central business district (CBD) is one of the everyday problems that drivers are faced with. The consequences of this problem are the congestions on the network, the increase in fuel consumption, additional pollution of the environment, etc.

Parking demands in the CBD can be affected in many ways. For example, the rise in parking price and prohibition of the entrance during certain periods of the day are some of them. The aim of all the strategies is to discourage the users from using their own vehicles when going to the CDB. Nevertheless, a certain number of users (often not a small one) come to the $\mathrm{CBD}$ in their own vehicles and then the problem of parking those vehicles becomes important. Various ways for the rationalization of controlling these demands were developed, and one of them was the idea of the parking space reservation, which is the topic of this paper.

The system with reservations functions when the users contract an operator (who controls the parking demands) via telephone or mobile applications. The users give the information needed for their reservation such as maximum walking time, maximum price, maximum length of stay, etc. The focus of this paper will be on the information given about the time needed to reach the location and the duration of parking. On their own motives for parking, which remain known only to the user, they can estimate the duration of parking. They can also estimate the time needed to reach the parking space based on their own experience and driving habits. The information about the occupancy of the parking space is very important to the operator, and our methodology gives contribution as one decision-support system. Based on the appropriate estimation of the parking space occupancy, the capacity of the parking garage can be better exploited.

The aim of the model shown in this paper is to estimate the total occupancy of a parking space by one user. The parking space occupancy can be defined as the time between the user's telephone/application reservation and the moment they leave the parking space. As far as the authors are concerned, until now, in literature, the occupancy of a parking space has not been considered in this way.

The model proposed in this paper estimates the occupancy of each individual parking space in the system by the user who send their request at a certain time. Information like this would make it a lot easier for the operator (or software) to gain better control of the 
available parking spaces. Other than that, this model can help us decide whether to accept the request for reservation or not. If the request is denied, the operator sends the user a more realistic waiting time for the potential reservation. This is possible through the methodology proposed in this paper, and this approach is a novelty in literature, as far as the authors are considered.

FLS is very suited for this problem because occupancy of a parking space, in a system with reservations, is characterized by emphasized uncertainty. In the real application of the proposed methodology, every new user represents one new training pair for an NN, and as time passes, the system becomes so "smart" that it can recognize the habits and the behaviour of the users and make the decisions accordingly. In the following sections, this approach is explained in detail and verified through a numerical example.

In the last few years, many authors have been dealing with the problems of the parking system with reservations. In their paper [1] the authors researched how to control parking with dynamic change of price so that both the users and the parking garage benefit the most. In their paper [2] the authors suggested an intelligent parking system with reservations for improving the quality of service by optimizing the schedule of accepting the parking demands. The integration of the "car sharing" strategy and the parking system with reservations was considered by the authors in paper [3]. In paper [4] the authors developed an intelligent model of controlling the parking system which implies the user's help for finding an empty parking space in the garage itself. They showed that, by applying this system, the fuel consumption can be reduced by $80 \%$. An example of an application of the "ZigBee network" in establishing an intelligent parking system with reservations can be found in paper [5]. For all the test examples it was shown that the total user time when applying the suggested model based on the Markov chains, is reduced from $14 \%$ to $34 \%$. The use of a "Smartphone" with the aim of optimizing the parking system with reservations can be found in paper [6]. The optimization process was created to minimize the total losses of the users. A flaw in this model is that it implies an "ideal" user's estimation about the time of arriving to the parking space. In paper [7] the authors developed a model of controlling the parking demands on the internet. The application for mobile phones which enables payments, finding the shortest route and the parking space reservation was developed. Software which overlooks the assignment of parking spaces in real time was also created. In paper [8] the authors developed a multi-criteria approach which chooses the most favourable reservation in the parking system based on the users' preferences. Then, a special application leads the user to the parking space by an optimal route. Examples have shown the possibilities of applying this model. In paper [9] the authors dealt with the analysis of the parking system with reservations in the case of on-street parking. The results of the suggested model, which were based on simulation, showed all the advantages of this model which were reflected in the easier and better finding of the parking space.

Some of the important earlier studies in this area can be found in the work of the following authors: the aim of paper [10] is to study the impacts of a reservation system for on-street parking. The authors concluded that the system for on-street parking has resulted in a more efficient distribution of available parking spaces among drivers searching for parking. A study in paper [11] analyses the factors which determine the choice of parking place of visitors to the central business district. The author finds that the walking time greatly influenced the visitor's choice. Further, it could be also noted that visitors seemed just as inclined to use "illegal parking" as an "ideal" parking place on the street. Paper [12] develops a model by relating the main objectives of the parking system, such as choice, allocation, etc. After that, the authors discussed the relationship between these objectives to find the best model for the parking analysis. Paper [13] describes a simulation model which was used to estimate several strategies for improving urban on-street parking systems. The experiments were performed with the model to determine how newer meter technologies might affect the parking revenues collected by the city government. Paper [14] presents a model that takes into account the parking search behaviour of drivers. The applications of the model showed that long-term experience does not necessarily lead to better choices. The problem of minimum parking requirements was discussed in paper [15]. Paper [16] presents a model for determining the maximum number of cars by zones in view of the capacity of the road network and the number of parking spaces available. A sensitivity analysis based on the heuristic algorithm has been developed to solve the proposed bi-level car ownership problem and it has been illustrated with a numerical example. Paper [17] describes the parking linear demand models for private cars and light freight vehicles developed as part of a parking demand study that was completed in Hong Kong in 1995. Paper [18] describes a behavioural model of parking choice with drivers' perceptions of waiting times at car parks based on the parking guidance and information (PGI) signs. This model was used to predict the influence of PGI signs on the overall performance of the traffic system. In paper [19] some parking pricing strategies are proposed and, for that purpose, some optimization models are formulated. Paper [20] proposes a real-time optimization approach to the parallel-parking control problem. A numerical simulation is demonstrated to illustrate the effect of the proposed method. 
In deterministic models for controlling parking with reservations, the duration of parking and the time in which the user reaches the parking space are shown as exact values. Such a setting is not often possible in practice and it can lead to the "precisely wrong" model of control.

The application of approximate reasoning is convenient when solving the problem of controlling the parking system. This is justified by the fact that the parameters of this system depend on are not of an exact nature (e.g. the time of driving to the parking space). The examples of such application in solving the problem can be found in the following papers [2126]. Based on the drivers' knowledge, in paper [21] the application for the control of the parking process was developed. The computer simulation of the parking control was executed for the purpose of confirming the applied methodology. A reservation pricing model that makes reservation prices equivalent to the value of saved searching time has been developed in paper [22]. The hybrid fuzzy controller for autonomous parking system was developed in paper [23]. Paper [24] proposes a methodology for predicting real-time parking space availability in the parking systems with reservation. New software, based on a fuzzy logic system, has been developed as driver assistance during parking and presented in paper [25]. Paper [26] establishes an index system for parking spaces to evaluate the performance of the parking system. This evaluation has been carried out through operational efficiency and the service level of each parking space in the observed parking system.

FLS and ANFIS are widely used methods for solving various traffic engineering problems. Many authors gave the contribution in this field, and some of them can be found in the recently published papers [27, 28]. For example, in paper [27] the authors describe the problem of choice of road route under conditions of uncertainty which the drivers face as they carry out their task of transportation. In paper [28] the authors investigate the influence of various parameters on planning the location for the city logistics terminal within the discrete network.

The second part of the paper shows the setting up of the problem and presents the model for the estimation of the parking space occupancy. In the third part, the model is tested on randomly generated pairs of input data, while the last section of the paper is reserved for the conclusive considerations and the display of future studies.

\section{NEURO-FUZZY MODEL FOR CONTROLLING PARKING SYSTEMS}

Let us suppose that the parking system with reservations is in place. The first limitation is that a parking space can be reserved only at the moment the user starts their travel, i.e. from their origin. There are systems in which it is possible to reserve a parking space before the travel starts (a few hours or even a day ahead), but they are not considered in this model. This model could also be applied if the user provided information about the time and place of their origin. The question of the travel origin can be a sensitive one for the user and of personal nature. To mitigate this, the user does not have to provide the exact address they start their travel from, but an approximate location (a street or an intersection nearby). Moreover, the confidentiality of such provided information would also be guaranteed to the user.

Parking areas have "classical" parking spaces and if there is a system with reservations, the spaces which can be reserved. The concept of the parking space occupancy by the user is introduced. This value represents the sum of time the user needs to reach the parking space which they reserved and the actual time of parking. In the system with reservations, a parking space is considered to be occupied from the moment the reservation has been accepted. Of course, this kind of service is additionally charged. This paper has addressed the subject problem by suggesting the application of the FLS and ANFIS models. The methodology is present in the form of a flowchart in Figure 1.

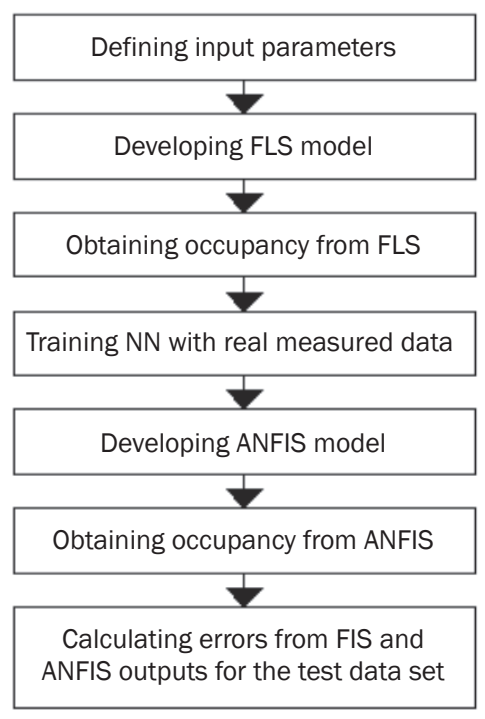

Figure 1 - FLS and ANFIS models

The travel time to the parking space $\left(X_{1}\right)$ is obtained via Google application “Google Maps - Live traffic". This application evaluates the travel time from the origin to the destination on the basis of the historical data about the vehicle flow and the speed of single vehicles in the flow, provided by the users' mobile phones. This Google application is also used for vehicle navigation through the network by offering routes with the shortest travel time, in real time. 
For the cities which are not covered by this application, the link travel time can be determined approximately. This time can be evaluated by the time the vehicle spends on the link. Let us mark the vehicle travel time by $t_{i j}$ on link $(i, j)$. Travel time $t_{i j}$ is calculated by using the widely known formula [29]:

$t_{i j}=t_{i j}^{0}\left[1+\alpha\left(\frac{q_{i j}}{c_{i j}}\right)^{\beta}\right]$

$t_{i j}^{0}=\frac{l_{i j}}{v_{i j}}$

where:

$t_{i j}^{0}$ - travel time on link $(i, j)$ in the function of the free flow speed [s];

$l_{i j}$ - link length $(i, j)[\mathrm{m}]$;

$v_{i j}$ - free flow speed [veh/h];

$q_{i j}$ - flow on link $(i, j)[\mathrm{veh} / \mathrm{h}]$;

$c_{i j}$ - link capacity $(i, j)[\mathrm{veh} / \mathrm{h}]$;

Empirically, the parameter values were obtained: $\alpha=0.15$ and $\beta=4$. The link capacity and the flow on the link are the pre-timed known values. The flow is estimated on the basis of historical data.

If we mark by $N_{k}$ the set of links through which the $k$-th user has passed from the origin to the destination, and by $d_{j}$ the average delay time at the $j$-th intersection [30], its total evaluated travel time is:

$t_{i j}^{k}=\sum_{i j=1}^{\left|N_{k}\right|} t_{i j}+\sum_{j=1}^{\left|N_{k}\right|} d_{j}$

The users themselves evaluate how long the vehicle will be parked. However, the users cannot be expected to determine the exact parking time (i.e. 27 $\mathrm{min})$, so they are given the time intervals which are acceptable to them for the evaluation. It is predicted that the parking could not last longer than $T_{\max }$, and according to that, this time should be divided into certain intervals. For example, if $T_{\max }=180 \mathrm{~min}$, time intervals could be: up to $15 \mathrm{~min}$; from 15 to $30 \mathrm{~min}$; from 30 to $60 \mathrm{~min}$; from 60 to $90 \mathrm{~min}$; from 90 to $120 \mathrm{~min}$; from 120 to $150 \mathrm{~min}$ and from 150 to $180 \mathrm{~min}$.

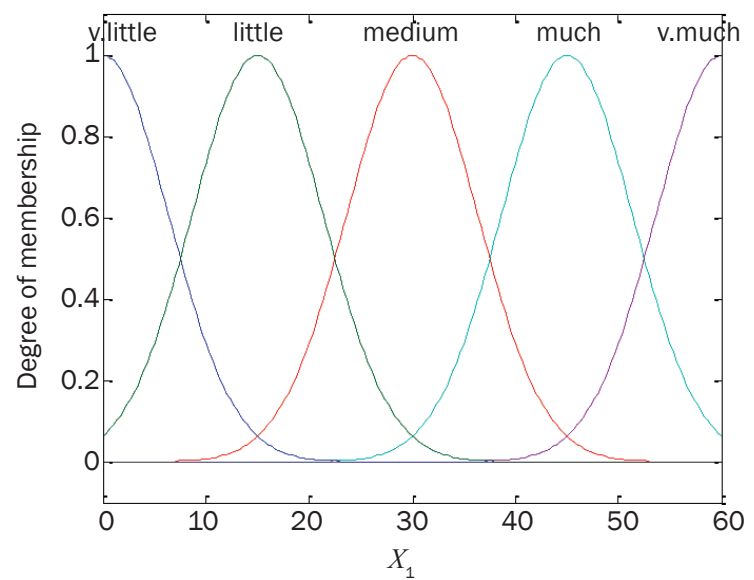

On the basis of the interval the user chooses, the parking price is formed. If the user is late, i.e. oversteps the time they have chosen, they will have to pay additionally. In that way, we influence the user to respect the interval he has chosen. This model doesn't include the parking price formation. Based on the interval chosen by the user, the medium of that interval is taken as the input value $\left(X_{2}\right)$. For example, for the interval of 30-60 minutes, it is estimated that the user will stay for 45 minutes.

It is clear that both of input values are not exact and because of that they cannot be determined precisely, so their presentation by the fuzzy sets is justified. The appearance of the membership functions of these two values is shown in Figure 2. As the longest travel time, 60 minutes (for $X_{1}$ ) was predicted, while for the longest parking time $T_{\max }=180 \mathrm{~min}$ (for $X_{1}$ ) was predicted.

For the input criteria description, the Gauss functions were used as the membership functions (gmf, Figure 2). The Gauss functions were chosen because they are available for manipulation when adjusting the FLS, as well as for the fact that they describe the input variables well and provide the satisfactory system sensibility.

The input value parameters $X_{1}$ are: $K_{x 1}$ v.little (very little) gmf $(6.372,0) ; K_{x 1}$ little gmf $(6.372,15) ; K_{x 1}$ medium gmf $(6.372,30) ; K_{x 1}$ much gmf $(6.372,45) ; K_{x 1}$ v.much (very much) gmf $(6.372,60)$. The input value $X_{2}$ parameters are: $K_{x 2}$ v.little gmf $(19.12,0) ; K_{x 2}$ little gmf $(19.12,44.52) ; K_{x 2}$ medium gmf $(19.12,90) ; K_{x 2}$ much gmf $(19.12,135) ; K_{x 2}$ v.much gmf $(19.12,180)$.

The output value represents the parking space occupancy $(Y)$. It is logical that it cannot be calculated as a plain sum of two input values but it is presented in the following linear form:

$Y=a X_{1}+b X_{2} \quad[\mathrm{~min}]$

where: $a$ and $b$ are the delay coefficients.

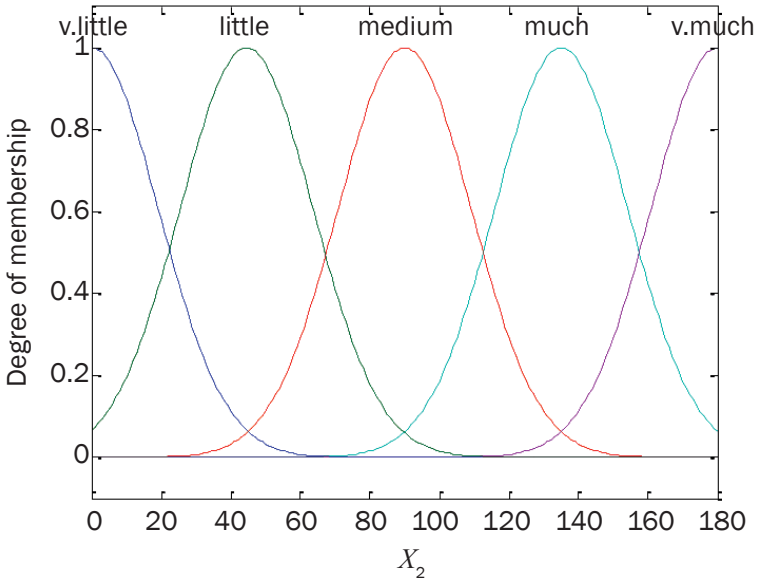

Figure 2 - The input values in FLS 
It is necessary to determine empirically the a and b coefficients. Therefore, a research was carried out on the location of the parking garage "ZeleniVenac" in Belgrade.

On the sample of 1,000 users, the travel time to the parking space and the duration of parking were tested. The users provided an approximate location of the travel origin and chose an interval of parking duration from the proposed set, as previously stated. The travel times were obtained by the application of "Google Maps - Live traffic".

For each of them, the actual travel times were recorded between the moment their parking request was received and the moment their vehicle left the parking space. The first 950 input-output pairs of information will be used for the model training, while the other 50 will be used for testing.

Based on the input and output values, the FLS of the Sugeno type is formed. The intervals in which the input and the output values can be found are given in Table 1.

Table 1 - The domain of functions $X_{1}, X_{2}$ and $Y$

\begin{tabular}{|c|c|}
\hline Function & Domain (min) \\
\hline \hline$X_{1}$ & {$[5,60]$} \\
\hline$X_{2}$ & {$[5,180]$} \\
\hline$Y$ & {$[10,240]$} \\
\hline
\end{tabular}

The function domains given in Table 1 can be determined in other ways, depending on the specific conditions of the parking space.

After determining the FLS input parameters, the base of the rules which is given in Table 2 should be formed. Depending on the deviations from the real times of coming to and going from the parking spaces and on the estimation of these times (based on 950 input-output values), the parameters $a$ and $b$ are evaluated. The estimation is performed on an expert basis. Their value is bigger than 1 because the delay includes both cases of time deviations, and when the user comes earlier or is late. In other words, these values are evaluated by the experts and they are based on the absolute value of the difference in input value deviations.

Table 2 - Rule base

\begin{tabular}{|c|c|c|c|}
\hline \multirow{2}{*}{ Rule } & \multicolumn{2}{|c|}{ IF $\left(X_{1}\right.$ and $\left.X_{2}\right)$} & THEN \\
\cline { 2 - 4 } & $X_{1}$ & $X_{2}$ & $Y$ \\
\hline \hline 1. & V.little & V.little & $1.439 \cdot X_{1}+1.262 \cdot X_{2}$ \\
\hline 2. & V.little & Little & $1.439 \cdot X_{1}+1.183 \cdot X_{2}$ \\
\hline 3. & V.little & Medium & $1.439 \cdot X_{1}+1.104 \cdot X_{2}$ \\
\hline \multicolumn{4}{|c|}{$\ldots$} \\
\hline 23. & V.much & Medium & $1.115 \cdot X_{1}+1.104 \cdot X_{2}$ \\
\hline 24. & V.much & Much & $1.115 \cdot X_{1}+1.074 \cdot X_{2}$ \\
\hline 25. & V.much & V.much & $1.115 \cdot X_{1}+1.053 \cdot X_{2}$ \\
\hline
\end{tabular}

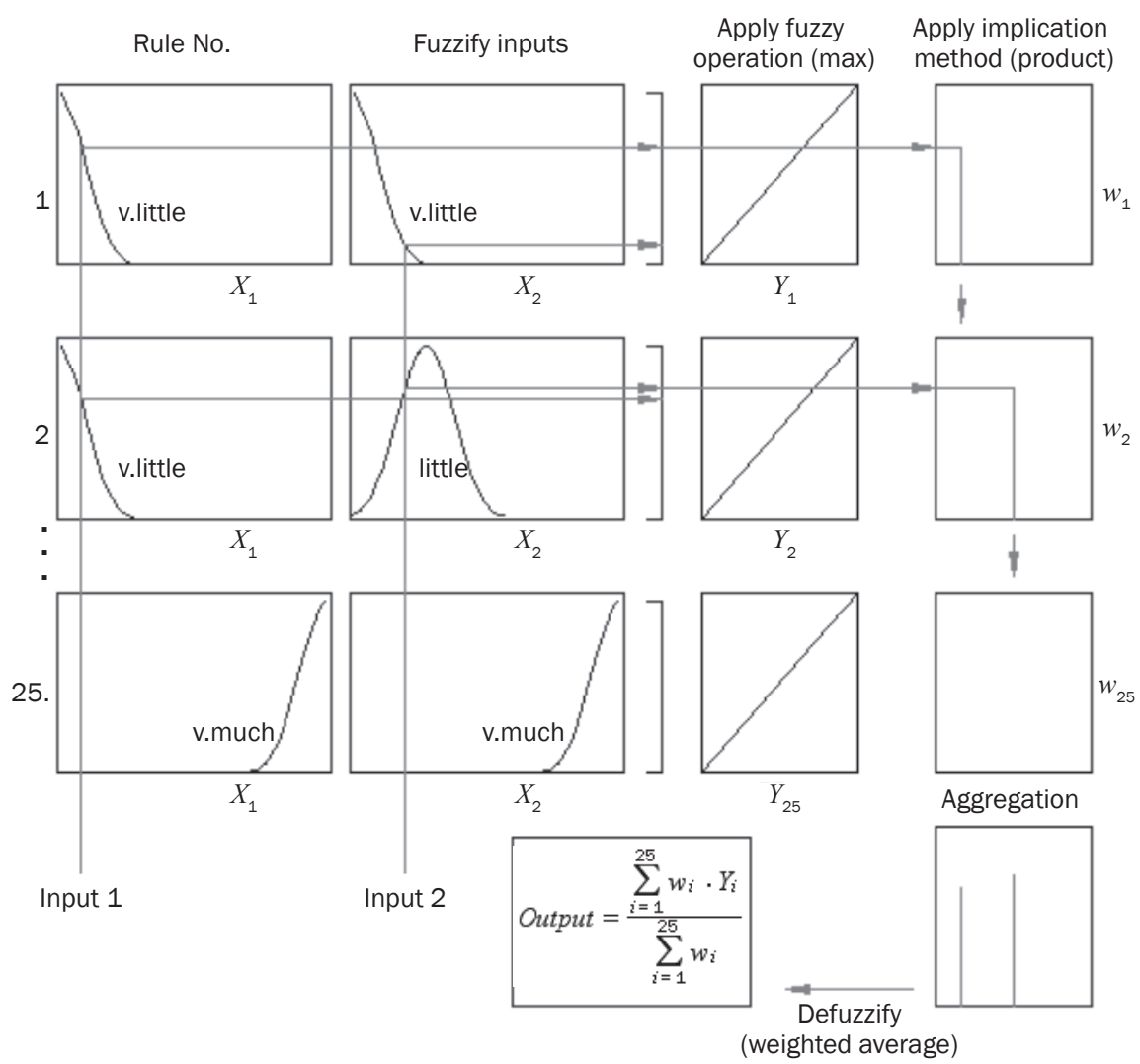

Figure 3 - Defuzzification of Sugeno FLS 
The first two parts of the fuzzy inference process, fuzzifying the inputs and applying the fuzzy operator, are exactly the same as in Mamdani FLS. The main difference between Mamdani and Sugeno is that the Sugeno output membership functions are either linear or constant. Sugeno FLS assumes the applying product type of implication and sum aggregation method. Figure 3 shows the process for defuzzification, based on Table 2. The final output of the system is the weighted average of all rule outputs.

Because of the extreme sensitivity and unpredictability of the system, and regarding the nature of the input parameters, a neuro-fuzzy system was formed. With the already mentioned 950 input-output pairs of information, an NN was trained with the aim of finely tuning the parameters of membership functions.

\subsection{The neuro fuzzy-logical system architecture}

Because of everything stated, a mapping of FLS into ANFIS was performed (Figure 4). The ANFIS was used for the additional adjustment of the FLS membership functions. It was done by the NN training. In this paper, a backpropagation algorithm was used for training ANFIS.

Figure 4 shows the mechanism of fuzzy concluding for obtaining the output function, based on the input values $\left[x_{1}, x_{2}\right]$. The weight coefficients $\omega_{1}$ and $\omega_{2}$ were obtained from the degree of membership in the premise, while the output function $y$ is the node each of THEN part of the rule. Each of the nodes on the net- work in the same layer performs the function of the same type. With $O O_{i}^{j}$ the exits of the $i$-th node in the $j$-th layer were marked.

Layer 1 . The nodes of the first layer represent verbal categories of the input variables which are quantified by fuzzy sets. Each node of the first layer is an adaptive node and it is described by the membership function $\mu_{x_{i}}\left(x_{i}\right), i=1, \ldots, 5$. The membership functions are described in the shape of Gauss functions which are characterized by two parameters $c$ (the function centre) and $\sigma$ (the function width).

$\operatorname{Gaussian}(x, c, \sigma)=e^{-\frac{1}{2}\left(\frac{x-c}{\sigma}\right) 2}$

Since the fuzzy rules are expressed as "If - premise, Then - consequence", the input variables' categories which are qualified by fuzzy sets are shown by the adaptive nodes of the first layer.

Layer 2. Each node of this layer counts a minimum value of the two input values of the adaptive NN. The output values of the second layer nodes represent the rule significances.

$O_{i}^{2}=\omega_{i}=\mu_{A i}\left(x_{1}\right) \cdot \mu_{B i}\left(x_{2}\right)$

Layer 3. Each $i$-th node (of total $n$ ) on this layer calculates the total weight of the $i$-th rule from the rule base according to the expression:

$O_{i}^{3}=\bar{\omega}_{i}=\frac{\omega_{i}}{\sum_{i=1}^{n} \omega_{i}}, \quad i=1,2, \ldots, n$

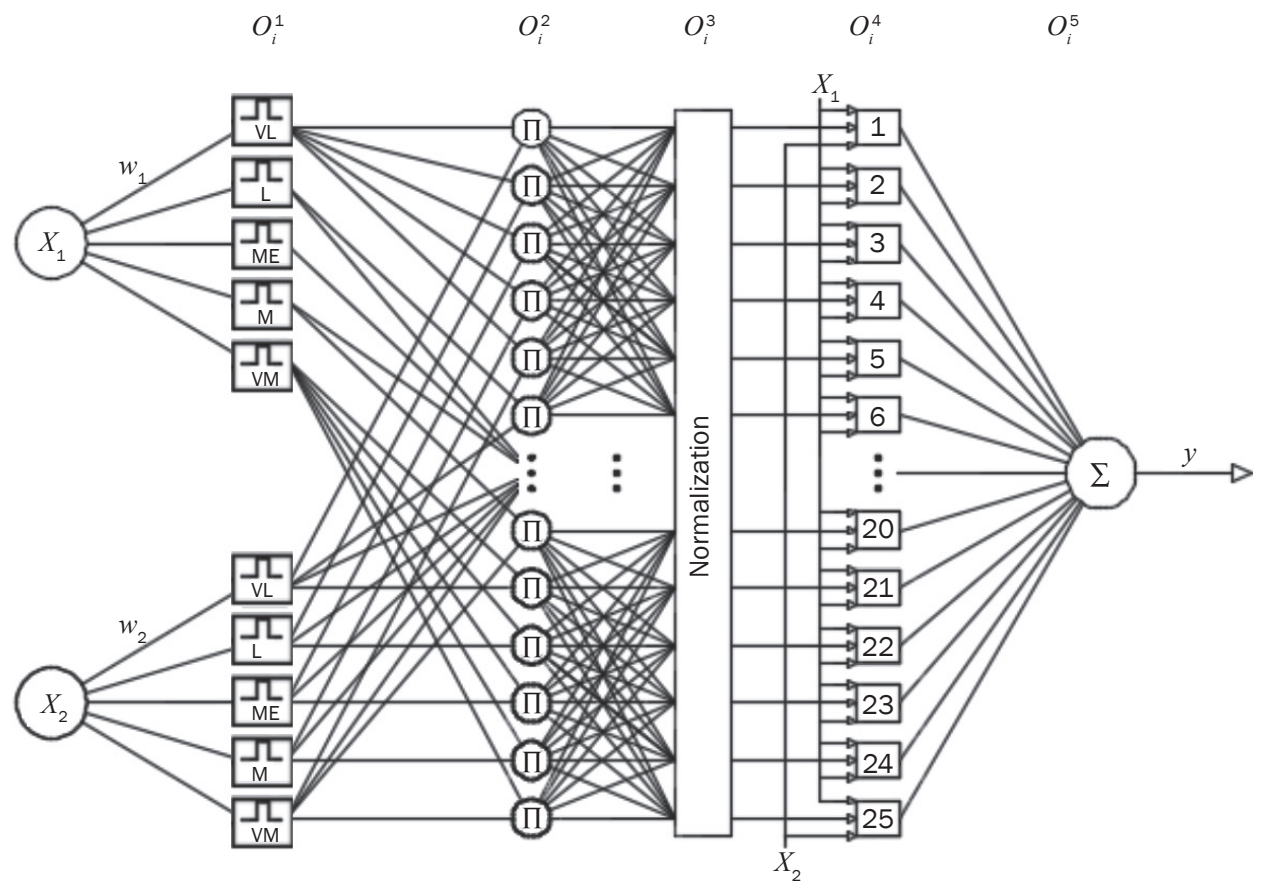

Figure 4 - The neuro-fuzzy net architecture and the exits' generation 
Layer 4 . The fourth layer has 25 adaptive nodes which represent the output value $Y$ (the parking space occupancy by the user). Each node of this layer is connected with the normalized neuron from the previous layer. Defuzzification of neurons is performed as follows:

$O_{i}^{4}=\bar{\omega}_{i} \cdot f_{i}=\bar{\omega}_{i} \cdot\left(p_{i} x_{1}+q_{i} x_{2}+r_{i}\right), \quad i=1,2, \ldots, n$

where $n$ is the total number of rules in the fuzzy rules' base, while $p, q$ and $r$ are the consequence parameters of the $i$-th rule.

Layer 5. The only node of the fifth layer is the fixed node in which the output result of ANFIS is calculated. It is a fuzzy set with determined membership degrees of the possible values of $Y$ for the determined park ing user. Defuzzification is performed in the fifth level node. The output value is a real number which is in the interval $[10,240]$ :

$O_{i}^{5}=\sum_{i} \bar{\omega}_{i} \cdot f_{i}=\frac{\sum_{i} \omega_{i} f_{i}}{\sum_{i} \omega_{i}}$

\subsection{ANFIS learning}

The output function of ANFIS, shown by Formula 10, is in the linear dependence of the parameters from the consequences of the fuzzy rule.

$$
\begin{aligned}
f= & \bar{\omega}_{1} \cdot f_{1}+\bar{\omega}_{2} \cdot f_{2}=\left(\bar{\omega}_{1} \cdot x_{1}\right) \cdot p_{1}+\left(\bar{\omega}_{1} \cdot x_{2}\right) \cdot q_{1}+ \\
& \left(\bar{\omega}_{2} \cdot x_{1}\right) \cdot p_{2}+\left(\bar{\omega}_{2} \cdot x_{2}\right) \cdot q_{2}
\end{aligned}
$$

Then, for the $k$-th pair of the input-output pairs of information, the output from the ANFIS net $\left(E_{k}\right)$ can be calculated as:

$$
E_{k}=\left(T_{k}-O_{k}\right)^{2}
$$

where $T_{k}$ and $O_{k}$ are the desired output and the output from ANFIS, respectively. Then, for the whole set of 950 input-output pairs for learning, it is possible to calculate the average error $E$ as:

$$
E=\sqrt{\frac{\sum_{k=1}^{950} E_{k}}{950}}
$$

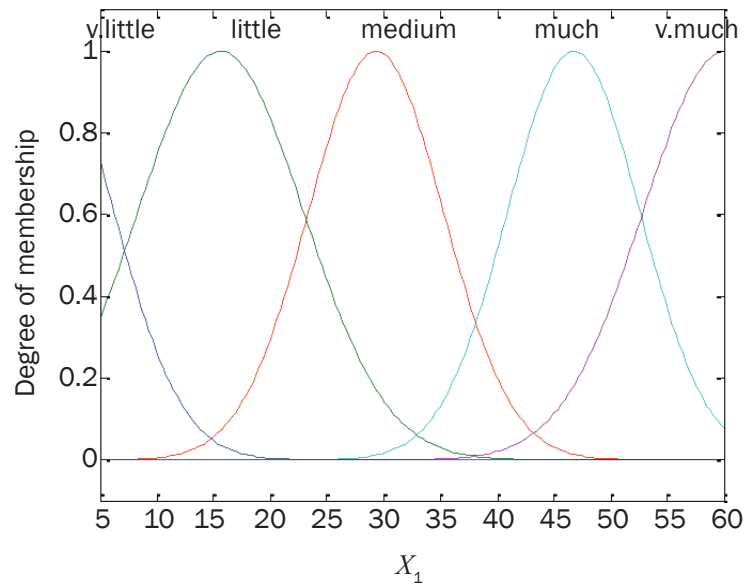

In the backward pass, the error signals are propagated and the antecedent parameters are updated according to the chain rule [31].

The activation functions of the neurons are needed so the network could be capable of learning the non-linear functions. Without non-linearity, the neurons would have the same possibilities as a plain perceptron network (which consists only of the inputs and the outputs). As the activation function in the ANFIS models most often the so-called "bell-function" is used in the following form

$y=\left(1+\left(x-\frac{s}{r}\right)^{t}\right)^{-1}$

where: $r, s$ and $t$ are the control parameters which adjust the slope, the centre and the width of a bellshaped function, respectively.

The algorithm which is mostly used for the NN training is the backpropagation [32]. Backpropagation learns the schemes comparing the NN output with the desired output and calculates the errors for each node on the network. The NN adjusts the links weight according to the error values assigned to each node. The calculation starts from the output layer, over the hidden layers, to the output layer. After the parameter modification, new inputs are brought to the network. The learning is not stopped until the network is able to give outputs with satisfactory accuracy.

During the learning process, the membership functions of fuzzy sets are finely tuned through the numerical pairs of the input-output data. The obtained membership functions are shown in Figure 5.

The parameters of the input value $X_{1}$ are: $K_{x 1}$ v.little gmf $(5.979,0.2171) ; K_{x 1}$ little gmf $(7.316,15.6)$; $K_{x 1}$ medium gmf $(5.964,29.3) ; K_{x 1}$ much gmf (5.855, $46.75) ; K_{x 1}$ v.much gmf $(7.22,59.93)$. The parameters of the input value $X_{2}$ are: $K_{x 2}$ v.little gmf (19.12, -0.0621); $K_{x 2}$ little gmf $(19.2,44.92) ; K_{x 2}$ medium gmf $(19.15,90.04) ; K_{x 2}$ much gmf $(18.08,135.1) ; K_{x 2}$ v.much gmf $(19.08,180)$.

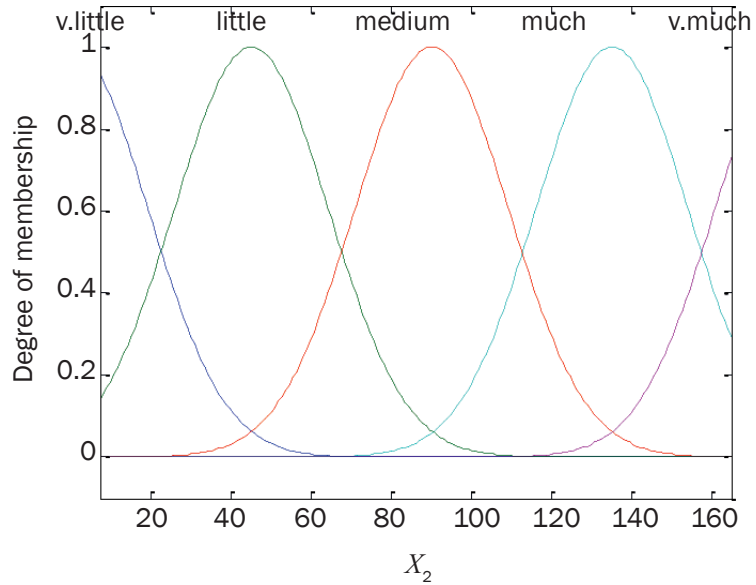

Figure 5 - Membership functions after the NN training 


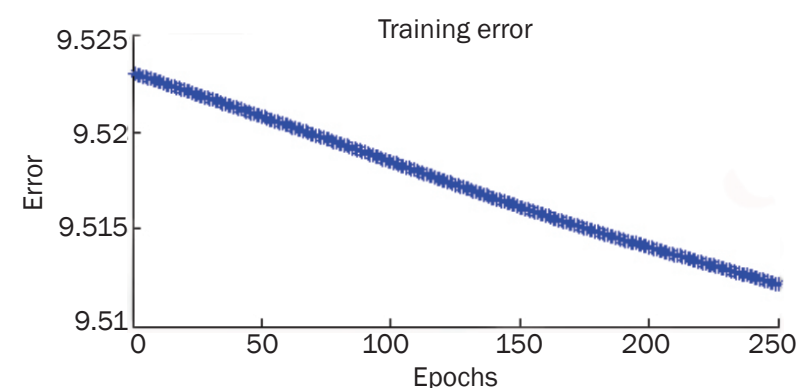

Figure 6 - The error reduction through epochs

After 250 epochs, the error has been reduced from 9.525 to 9.51 . The process of error reduction through the epochs is given in Figure 6. In the numerical example, the results also given by ANFIS on unknown input pairs, i.e. on those which are not used for the NN training, will be shown.

Figure 7 shows the 3D dependence of the input and output values. In other words, the picture shows the sensibility of the output value ("the occupancy") related to the input ones (the estimated travel time and the parking time by the users).

The sensitivity of outputs on the input parameters, when checking the occupancy of the parking space, is very high. After training NN by the realistic output-input data, a bit more complex 3D structure of this dependency appears, in regard to FLS, which should lead to a more precise evaluation of the output value (Figure 7 ).

\section{A NUMERICAL EXAMPLE AND THE TESTING RESULTS}

The suggested ANFIS model for the evaluation of the occupancy of a parking space in the system with reservations will be tested on the last 50 input-output pairs. The testing results are to be shown in Table 3. The testing was performed by three models. The first model (marked $\alpha$ ) which performs the prediction of the parking space occupancy is simple and it is based on the already known linear equation:

$$
Y^{\alpha}=a^{\alpha} X_{1}+b^{\alpha} X_{2}
$$

It is possible to determine the $a^{\alpha}$ and $b^{\alpha}$ parameters simply, from 950 input-output data (the same ones used for the NN training). Let us mark by $X_{1}^{\text {real }}(k)$ the real value of input $X_{1}$ for the $k$-th user, and let us mark by $X_{1}^{\text {est }}(k)$ the estimated value of input $X_{1}$ for the $k$-th user. If $N$ is used to mark the set of all the users (in this case 950), the $a^{\alpha}$ parameter can be calculated as follows:

$a^{\alpha}=\frac{1}{|N|} \cdot \sum_{k=1}^{|N|} \frac{\left|X_{1}^{\text {real }}(k)-X_{1}^{\text {est }}(k)\right|+X_{1}^{\text {est }}(k)}{X_{1}^{\text {est }}(k)}$

In the same way, it is possible to obtain parameter $b$. Let us mark by $X_{2}^{\text {real }}(k)$ the real value of input $X_{2}$ for the $k$-th user, and let us mark by $X_{2}^{\text {est }}(k)$ the estimated value of input $X_{2}$ for the $k$-th user. If $N$ is used to mark the set of all the users (in this case 950 ), the $b^{\alpha}$ parameter can be calculated like this:

$b^{\alpha}=\frac{1}{|N|} \cdot \sum_{k=1}^{|N|} \frac{\left|X_{2}^{\text {real }}(k)-X_{2}^{\text {est }}(k)\right|+X_{2}^{\text {est }}(k)}{X_{2}^{\text {est }}(k)}$

The thus obtained results are given in the seventh column of Table 3 and marked by $Y^{\alpha}(k)$. The results obtained by training of the FLS are presented in column nine and marked by $Y^{F L S}(k)$, while the output values from the ANFIS model are given in the eleventh column of Table 3 and marked as $Y^{A N F I S}(k)$. $Y^{\text {real }}(k)$ marks the real (recorded) value of the parking space occupancy by the $k$-th user.

The set of input-output pairs for the testing is marked by $M . E^{\alpha}, E^{F L S}$ and $E^{A N F I S}$ mark the errors in the given models, respectively. The marked errors are calculated in the following way:

$$
\begin{aligned}
& E^{\alpha}=\frac{1}{|M|} \cdot \sum_{k=1}^{|M|}\left|Y^{\text {real }}(k)-Y^{\alpha}(k)\right| \\
& E^{F I S}=\frac{1}{|M|} \cdot \sum_{k=1}^{|M|}\left|Y^{\text {real }}(k)-Y^{F I S}(k)\right| \\
& E^{\text {ANFIS }}=\frac{1}{|M|} \cdot \sum_{k=1}^{|M|}\left|Y^{\text {real }}(k)-Y^{\text {ANFIS }}(k)\right|
\end{aligned}
$$

In the end, the best model will be chosen by the criterion of the smallest value of $E$ error (min).
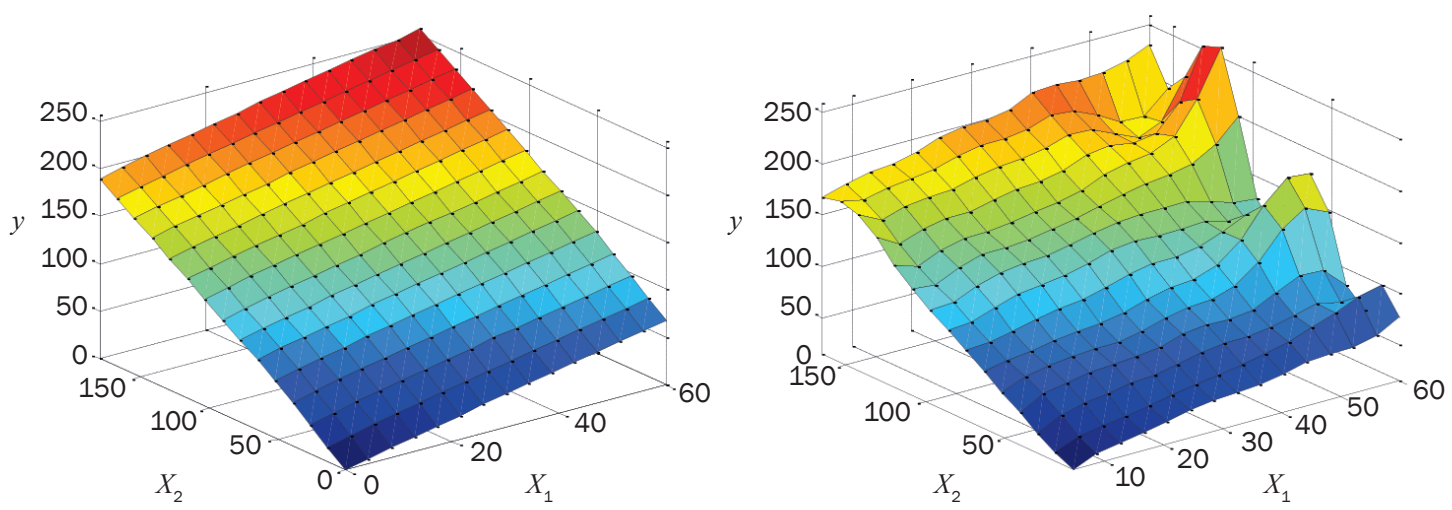

Figure 7 - 3D dependence of FLS (left) and ANFIS (right) 
Table 3 - Testing of the proposed ANFIS model

\begin{tabular}{|c|c|c|c|c|c|c|c|c|c|c|c|}
\hline$k$ & $X_{1}^{\text {est }}$ & $X_{1}^{\text {real }}$ & $X_{2}^{\text {est }}$ & $X_{2}^{\text {real }}$ & $Y^{\text {real }}$ & $Y^{\alpha}$ & $E^{\alpha}$ & $Y^{F L S}$ & $E^{F L S}$ & $Y^{A A N F I S}$ & $E^{A N F I S}$ \\
\hline 1 & 8 & 14 & 45 & 49 & 63 & 60.05 & 2.95 & 63.76 & 0.76 & 59.5 & 3.5 \\
\hline 2 & 10 & 10 & 45 & 55 & 65 & 62.50 & 2.50 & 66.00 & 1.00 & 63 & 2 \\
\hline 3 & 6 & 12 & 7 & 12 & 24 & 15.15 & 8.85 & 16.90 & 7.10 & 17.8 & 6.2 \\
\hline 4 & 7 & 8 & 105 & 112 & 120 & 125.87 & 5.87 & 124.44 & 4.44 & 111 & 9 \\
\hline 5 & 22 & 21 & 105 & 91 & 112 & 144.20 & 32.20 & 141.32 & 29.32 & 132 & 20 \\
\hline 6 & 20 & 20 & 105 & 108 & 128 & 141.75 & 13.75 & 139.11 & 11.11 & 132 & 4 \\
\hline 7 & 19 & 17 & 105 & 116 & 133 & 140.53 & 7.53 & 137.99 & 4.99 & 132 & 1 \\
\hline 8 & 24 & 32 & 45 & 53 & 85 & 79.60 & 5.40 & 81.65 & 3.35 & 71.7 & 13.3 \\
\hline 9 & 24 & 29 & 45 & 31 & 60 & 79.60 & 19.60 & 81.65 & 21.65 & 71.7 & 11.7 \\
\hline 10 & 16 & 20 & 22 & 18 & 38 & 44.13 & 6.13 & 46.39 & 8.39 & 43.9 & 5.9 \\
\hline 11 & 25 & 22 & 7 & 14 & 36 & 38.36 & 2.36 & 38.26 & 2.26 & 42.4 & 6.4 \\
\hline 12 & 30 & 35 & 75 & 61 & 96 & 120.45 & 24.45 & 119.44 & 23.44 & 110 & 14 \\
\hline 13 & 32 & 41 & 75 & 67 & 108 & 122.89 & 14.89 & 121.67 & 13.67 & 113 & 5 \\
\hline 14 & 29 & 39 & 75 & 61 & 100 & 119.23 & 19.23 & 118.33 & 18.33 & 108 & 8 \\
\hline 15 & 29 & 34 & 75 & 83 & 117 & 119.23 & 2.23 & 118.33 & 1.33 & 108 & 9 \\
\hline 16 & 34 & 37 & 75 & 65 & 102 & 125.34 & 23.34 & 123.86 & 21.86 & 116 & 14 \\
\hline 17 & 35 & 31 & 105 & 93 & 124 & 160.08 & 36.08 & 155.59 & 31.59 & 145 & 21 \\
\hline 18 & 33 & 32 & 105 & 119 & 151 & 157.63 & 6.63 & 153.44 & 2.44 & 143 & 8 \\
\hline 19 & 28 & 28 & 105 & 90 & 118 & 151.53 & 33.53 & 147.88 & 29.88 & 137 & 19 \\
\hline 20 & 36 & 32 & 105 & 112 & 144 & 161.30 & 17.30 & 156.64 & 12.64 & 146 & 2 \\
\hline 21 & 34 & 41 & 135 & 129 & 170 & 192.38 & 22.38 & 184.50 & 14.50 & 170 & 0 \\
\hline 22 & 31 & 29 & 105 & 92 & 121 & 155.19 & 34.19 & 151.23 & 30.23 & 140 & 19 \\
\hline 23 & 32 & 41 & 105 & 98 & 139 & 156.41 & 17.41 & 152.34 & 13.34 & 142 & 3 \\
\hline 24 & 37 & 37 & 105 & 102 & 139 & 162.52 & 23.52 & 157.68 & 18.68 & 148 & 9 \\
\hline 25 & 35 & 35 & 45 & 46 & 81 & 93.04 & 12.04 & 93.74 & 12.74 & 84.5 & 3.5 \\
\hline 26 & 29 & 30 & 45 & 53 & 83 & 85.71 & 2.71 & 87.15 & 4.15 & 76.5 & 6.5 \\
\hline 27 & 29 & 25 & 75 & 89 & 114 & 119.23 & 5.23 & 118.33 & 4.33 & 108 & 6 \\
\hline 28 & 34 & 30 & 75 & 68 & 98 & 125.34 & 27.34 & 123.86 & 25.86 & 116 & 18 \\
\hline 29 & 32 & 37 & 75 & 79 & 116 & 122.89 & 6.89 & 121.67 & 5.67 & 113 & 3 \\
\hline 30 & 32 & 32 & 75 & 78 & 110 & 122.89 & 12.89 & 121.67 & 11.67 & 113 & 3 \\
\hline 31 & 44 & 54 & 75 & 72 & 126 & 137.55 & 11.55 & 134.32 & 8.32 & 122 & 4 \\
\hline 32 & 46 & 46 & 135 & 150 & 196 & 207.04 & 11.04 & 197.13 & 1.13 & 182 & 14 \\
\hline 33 & 43 & 49 & 165 & 175 & 224 & 236.89 & 12.89 & 223.56 & 0.44 & 217 & 7 \\
\hline 34 & 38 & 36 & 75 & 69 & 105 & 130.22 & 25.22 & 128.03 & 23.03 & 118 & 13 \\
\hline 35 & 39 & 41 & 75 & 76 & 117 & 131.44 & 14.44 & 129.06 & 12.06 & 119 & 2 \\
\hline 36 & 38 & 47 & 75 & 62 & 109 & 130.22 & 21.22 & 128.03 & 19.03 & 118 & 9 \\
\hline 37 & 47 & 48 & 75 & 63 & 111 & 141.22 & 30.22 & 137.57 & 26.57 & 127 & 16 \\
\hline 38 & 47 & 45 & 75 & 66 & 111 & 141.22 & 30.22 & 137.57 & 26.57 & 127 & 16 \\
\hline 39 & 45 & 55 & 45 & 56 & 111 & 105.25 & 5.75 & 104.22 & 6.78 & 91.4 & 19.6 \\
\hline 40 & 38 & 40 & 105 & 108 & 148 & 163.74 & 15.74 & 158.70 & 10.70 & 149 & 1 \\
\hline 41 & 41 & 37 & 105 & 116 & 153 & 167.41 & 14.41 & 161.79 & 8.79 & 151 & 2 \\
\hline 42 & 42 & 51 & 75 & 82 & 133 & 135.11 & 2.11 & 132.18 & 0.82 & 120 & 13 \\
\hline 43 & 47 & 45 & 75 & 60 & 105 & 141.22 & 36.22 & 137.57 & 32.57 & 127 & 22 \\
\hline 44 & 47 & 47 & 75 & 73 & 120 & 141.22 & 21.22 & 137.57 & 17.57 & 127 & 7 \\
\hline 45 & 48 & 43 & 75 & 67 & 110 & 142.44 & 32.44 & 138.65 & 28.65 & 130 & 20 \\
\hline 46 & 48 & 49 & 165 & 152 & 201 & 243.00 & 42.00 & 228.97 & 27.97 & 215 & 14 \\
\hline 47 & 58 & 72 & 22 & 29 & 101 & 95.43 & 5.57 & 91.69 & 9.31 & 90.9 & 10.1 \\
\hline 48 & 54 & 70 & 105 & 102 & 172 & 183.29 & 11.29 & 175.63 & 3.63 & 159 & 13 \\
\hline 49 & 54 & 63 & 105 & 120 & 183 & 183.29 & 0.29 & 175.63 & 7.37 & 159 & 24 \\
\hline 50 & 54 & 58 & 105 & 115 & 173 & 183.29 & 10.29 & 175.63 & 2.63 & 159 & 14 \\
\hline \multicolumn{6}{|c|}{ Average error } & \multicolumn{2}{|c|}{$E^{\alpha}=16.07$} & \multicolumn{2}{|c|}{$E^{F L S}=13.29$} & \multicolumn{2}{|c|}{$E^{A N F I S}=9.89$} \\
\hline
\end{tabular}


The deviation shows how many minutes the users were wrong in the estimation related to the one that has been calculated by the model proposed in this paper. It can be clearly seen that the ANFIS model gave the smallest error: 9.89 minutes. Somewhat worse results were obtained by FLS, with 13.29 minutes and the model based on delay coefficients with 16.07 minutes.

\section{CONCLUSION}

The model for evaluating the "occupancy" of the parking space by individual users in the system of parking with reservations has been proposed. The estimation is performed on the basis of data obtained about the travel time to the parking space and the information obtained from the users about the duration of parking. The "occupancy" of the parking space depends on many factors which cannot be determined exactly since it is necessary to adjust the parking system with reservations to real traffic conditions.

The proposed model represents a decision-making system. The main contribution of the presented methodology is the best possible estimation of parking space occupancy, which is very important. When in the parking system with reservations the decision maker (operator) has an information about the parking space occupancy, they will be able to control the parking spaces more precisely and rationally. They will also decide whether to accept or deny the request from a new user.

The numerical example verifies the proposed methodology and illustrates the benefits of applying ANFIS above FIS and solutions obtained from collecting the data.

The data for NN training are renewed after each new reviewed demand. In other words, as the number of demands increases, so do the data for the training of ANFIS. As the time passes, the model adapts itself to the real situation, which is the main potential of applying artificial intelligence in solving the given problem. The final result would be that, at a certain moment of time, this system becomes so "smart" that it can recognize the habits and the behaviour of the users and make decisions accordingly.

Future research could go in the direction of finding the most efficient exploitation of the suggested model in controlling the system of requests for parking with reservation. Furthermore, it is possible to consider a users' database development. By using this database, the NN could recognize an individual user and make a decision based on the previously manifested personal characteristics.

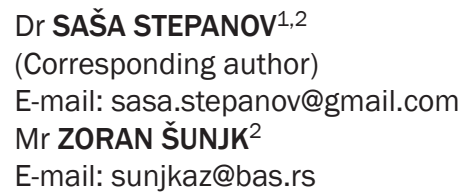

\section{Mr ĐORĐE ČABILOVSKI ${ }^{3}$}

E-mail: djcabilovski@gmail.com

${ }^{1}$ Fakultet za primenjeni menadžment, ekonomiju i finansije Jevrejska 24, 11000 Beograd, Srbija

2 BAS, Beogradska autobuska stanica a.d.

Železnička 4, 11000 Beograd, Srbija

${ }^{3}$ Ministarstvo odbrane Vojske Srbije

Gundulićeva BB, 23000 Zrenjanin, Srbija

\section{INTELIGENTNA KONTROLA PARKING MESTA U SISTEMU S REZERVACIJAMA}

\section{APSTRAKT}

Cilj sistema za parkiranje s rezervacijam je da smanji vreme putovanja korisnika do parking mesta, kao i da upravlja zahtevima za parkiranje u centralnim gradskim zonama. Kada se primenjuje sistem s rezervacijama, potrebno je da za svakog korisnika bude poznato vreme putovanja do parking mesta, kao i vreme trajanja parkiranja. Suma ova dva perioda predstavlja vreme "zauzetosti". Cilj ovog rada je da predloži model za određivanje ukupne zauzetosti parking mesta na osnovu: 1) vremena putovanja korisnika do parking mesta; 2) vremena trajanja parkiranja korisnika. Uzimajući u obzir da u model ulaze veličine čije vrednosti ne mogu biti egzanktno određene, koristimo fazi logički sistem. Neuronska mreža je trenirana na osnovu procenjenih vrednosti ulaznih parametara i realnih vrednosti izlaznih parametara. Na ovaj način dobijen je hibridni model fazi logike i neuronske mreže. Na kraju, dat je primer s realnim podacima koji prikazuju mogućnosti primene ovog modela.

\section{KLUUČNE REČI}

kontrola parking prostora; sistem s rezervacijama; fazi logika; neuronske mreže;

\section{REFERENCES}

[1] Polycarpou E, Lambrinos L, Protopapadakis E. Smart parking solutions for urban areas. Proceedings of the $14^{\text {th }}$ International Symposium on World of Wireless, Mobile and Multimedia Networks (WoWMoM), 4-7 June 2013, Madrid, Spain. IEEE; 2013. p. 1-6. Available from: https://www.computer.org/csdl/proceedings/wowmom/2013/5827/00/06583499-abs.html [Accessed 16 $16^{\text {th }}$ Oct. 2018].

[2] Doulamis N, Protopapadakis E, Lambrinos L. Improving service quality for parking lot users using intelligent parking reservation policies. Proceedings of the $27^{\text {th }}$ International Conference on Advanced Information Networking and Applications Workshops (WAINA), 25-28 March 2013, Barcelona, Spain. IEEE; 2013. p. 1392-1397. Available from: https://ieeexplore.ieee. org/abstract/document/6550590 [Accessed $16^{\text {th }}$ Oct. 2018].

[3] Kaspi M, Raviv T, Tzur M. Parking reservation policies in one-way vehicle sharing systems. Transportation Research Part B: Methodological. 2014;62: 35-50. Available from: https://www.sciencedirect.com/science/ article/pii/S0191261514000162 [Accessed 16 ${ }^{\text {th }}$ Oct. 2018].

[4] Venkateswaran V, Prakash N. Intelligent approach for 
smart car parking reservation and security maintenance system. IJRET: International Journal of Research in Engineering and Technology. 2014;3(2): 248-251.

[5] Shiyao C, Ming W, Chen L, Na R. The research and implement of the intelligent parking reservation management system based on zigbee technology. Proceedings of the $6^{\text {th }}$ International Conference on Measuring Technology and Mechatronics Automation (ICMTMA), 10-11 Jan. 2014, Zhangjiajie, China. IEEE; 2014. p. 741-744. Available from: https://ieeexplore.ieee.org/abstract/ document $/ 6802800$ [Accessed $16^{\text {th }}$ Oct. 2018].

[6] Chen Z, Yin Y, He F, Lin JL. Parking reservation for managing downtown curbside parking. Transportation Research Record: Journal of the Transportation Research Board. 2015;2498: 12-18. Available from: https://trrjournalonline.trb.org/doi/abs/10.3141/2498-02 [Accessed $16^{\text {th }}$ Oct. 2018].

[7] Sheelarani P, Anand SP, Shamili S, Sruthi K. Effective car parking reservation system based on internet of things technologies. Proceedings of the World Conference onFuturistic Trends in Research and Innovation for Social Welfare (Startup Conclave), 29 Feb - 1 Mar 2016, Coimbatore, India. IEEE; 2016. p. 1-4. Available from: https://ieeexplore.ieee.org/abstract/document/7583962 [Accessed $16^{\text {th }}$ Oct. 2018].

[8] Boudali I, Ouada MB. Smart parking reservation system based on distributed multicriteria approach. Applied Artificial Intelligence. 2017;31(5-6): 518-537. Available from: https://www.tandfonline.com/doi/abs/10.1080/ 08839514.2017 .1378275 [Accessed $16^{\text {th }}$ Oct. 2018].

[9] Tasseron G, Martens K. Urban parking space reservation through bottom-up information provision: An agent-based analysis. Computers, Environment and Urban Systems. 2017;64: 30-41. Available from: https://www.sciencedirect.com/science/article/pii/ S0198971517300364 [Accessed 16 th $^{\text {th }}$ Oct. 2018].

[10] Maher MJ, Birchall MC. Focus on planning for parking: A stochastic parking problem. Traffic Engineering \& Control. 1975;16(5): 220-223. Available from: https://www.sciencedirect.com/science/article/pii/ S0198971517300364 [Accessed $16^{\text {th }}$ Oct. 2018].

[11] Van der Goot D. A model to describe the choice of parking places. Transportation Research Part A: General. 1982;16(2): 109-115. Available from: https://www.sciencedirect.com/science/article/ pii/0191260782900036 [Accessed 16 ${ }^{\text {th }}$ Oct. 2018].

[12] Young W, Thompson RG, Taylor MA. A review of urban car parking models. Transport Reviews. 1991;11(1): 6384. Available from: https://www.tandfonline.com/doi/ abs/10.1080/01441649108716773 [Accessed $16^{\text {th }}$ Oct. 2018].

[13] Saltzman RM. An animated simulation model for analyzing on-street parking issues. Simulation. 1997;69(2): 79-90. Available from: http://journals.sagepub.com/ doi/abs/10.1177/003754979706900201 [Accessed $16^{\text {th }}$ Oct. 2018]

[14] Thompson RG, Richardson AJ. A parking search model. Transportation Research Part A: Policy and Practice. 1998;32(3): 159-170. Available from: https://www.sciencedirect.com/science/article/pii/ S0965856497000050 [Accessed 16 $16^{\text {th }}$ Oct. 2018].

[15] Shoup DC. The trouble with minimum parking requirements. Transportation Research Part A: Policy and Practice. 1999;33(7): 549-574. Available from: https://www.sciencedirect.com/science/article/pii/ S0965856499000075 [Accessed 16 $16^{\text {th }}$ Oct. 2018].

[16] Tam ML, Lam WH. Maximum car ownership under constraints of road capacity and parking space. Transportation Research Part A: Policy and Practice. 2000;34(3): 145-170. Available from: https://www.sciencedirect. com/science/article/pii/S0965856498000706 [Accessed $16^{\text {th }}$ Oct. 2018].

[17] Wong SC, Tong CO, Lam WC, Fung RY. Development of parking demand models in Hong Kong. Journal of Urban Planning and Development. 2000;126(2): 55-74. Available from: https://ascelibrary.org/doi/ abs/10.1061/(ASCE)0733-9488(2000)126:2(55) [Accessed 16 $6^{\text {th }}$ Oct. 2018].

[18] Thompson RG, Takada K, Kobayakawa S. Optimisation of parking guidance and information systems display configurations. Transportation Research Part C: Emerging Technologies. 2001;9(1): 69-85. Available from: https://www.sciencedirect.com/science/ article/pii/S0968090X00000310 [Accessed $16^{\text {th }}$ Oct. 2018].

[19] D’Acierno L, Gallo M, Montella B. Optimisation models for the urban parking pricing problem. Transport Policy. 2006;13(1): 34-48. Available from: https:// www.sciencedirect.com/science/article/abs/pii/ S0967070X05001034 [Accessed 16 $6^{\text {th }}$ Oct. 2018].

[20] Imae J, Yoshimura K, Zhai G, Kobayashi T. Real-time optimisation for parallel-parking control of fourwheeled vehicles. International Journal of Modelling, Identification and Control. 2009;6(3): 255-262. Available from: https://www.inderscienceonline.com/doi/ abs/10.1504/IJMIC.2009.024465 [Accessed $16^{\text {th }}$ Oct. 2018].

[21] Yasunobu S, Murai Y. Parking control based on predictive fuzzy control. Proceedings of the $3^{\text {rd }}$ International Fuzzy Systems Conference, 26-29 June 1994, Orlando, FL, USA. IEEE; 1994. p. 1338-1341. Available from: https://ieeexplore.ieee.org/abstract/document/343618 [Accessed 16 th Oct. 2018].

[22] Tsai MT, Chu CP. Evaluating parking reservation policy in urban areas: An environmental perspective. Proceedings of the $9^{\text {th }}$ International Conference of Eastern Asia Society for Transportation Studies, 2011. Eastern Asia Society for Transportation Studies; 2011. p. 272. Available from: https://www.jstage.jst.go.jp/article/eastpro/2011/0/2011_0_272/_article/-char/ ja/ [Accessed $16^{\text {th }}$ Oct. 2018].

[23] Wang Y, Zhu X. A robust design of hybrid fuzzy controller with fuzzy decision tree for autonomous intelligent parking system. Proceedings of the American Control Conference (ACC), 4-6 June 2014, Portland, OR, USA. IEEE; 2014. p. 5282-5287. Available from: https://ieeexplore.ieee.org/abstract/document/6859439 [Accessed $16^{\text {th }}$ Oct. 2018].

[24] Caicedo F, Blazquez C, Miranda P. Prediction of parking space availability in real time. Expert Systems with Applications. 2012;39(8): 7281-7290. Available from: https://www.sciencedirect.com/science/article/pii/ S0957417412001042 [Accessed 16 $6^{\text {th }}$ Oct. 2018].

[25] Matoba S, Yasunobu S. A cooperative parking system based on fuzzy intention. Proceedings of the Joint $7^{\text {th }}$ International Conference on Soft Computing and 
Intelligent Systems (SCIS) and $15^{\text {th }}$ International Symposium on Advanced Intelligent Systems (ISIS), 3-6 Dec. 2014, Kitakyushu, Japan. IEEE; 2014. p. 573-578. Available from: https://ieeexplore.ieee.org/ abstract/document/7044749 [Accessed 16 ${ }^{\text {th }}$ Oct. 2018].

[26] Sun DJ, Cheng JM, Zhang Y. An AHP-Fuzzy comprehensive evaluation model for parking lots in urban CBD area. Advances in Transportation Studies. 2015;37: 141-156.

[27] Pamucar D, Ćirović G. Vehicle route selection with an adaptive neuro fuzzy inference system in uncertainty conditions. Decision Making: Applications in Management and Engineering. 2018;1(1): 13-37. Available from: http://www.dmame.org/index.php/dmame/ article/view/1 [Accessed 28 ${ }^{\text {th }}$ Feb. 2019].

[28] Pamučar D, Vasin L, Atanasković P, Miličić M. Planning the City Logistics Terminal Location by Applying the Green-Median Model and Type-2 Neurofuzzy Network. Computational Intelligence and Neuroscience. 2016.
Available from: https://www.hindawi.com/journals/ cin/2016/6972818/abs/ [Accessed $28^{\text {th }}$ Feb. 2019].

[29] Munjal P, Pahl J. An analysis of the Boltzmann-type statistical models for multi-lane traffic flow. Transportation Research. 1969;3(1): 151-163.

[30] HCM 2010. Transportation Research Board, National Research Council, Washington, DC. Available from: https://trrjournalonline.trb.org/doi/book/10.5555/ 9780309160773 [Accessed $16^{\text {th }}$ Oct. 2018].

[31] Jang JS. ANFIS: adaptive-network-based fuzzy inference system. IEEE transactions on systems, man, and cybernetics. 1993;23(3): 665-685. Available from: https:// ieeexplore.ieee.org/abstract/document/256541 [Accessed 16 ${ }^{\text {th }}$ Oct. 2018].

[32] Rumelhart DE, Hinton GE, Williams RJ. Learning internal representations by error propagation. California Univ San Diego La Jolla Inst for Cognitive Science. Report No. 164453, 1985. Available from: http://www.dtic.mil/ docs/citations/ADA164453 [Accessed 16 ${ }^{\text {th }}$ Oct. 2018]. 